\title{
Radionuclide Methods in the Diagnosis of Sacroiliitis in Patients with Spondyloarthritis: An Update
}

\author{
Karina Zilber, M.D. ${ }^{1,3}$, Miguel Gorenberg, M.D. ${ }^{2,3}$, Doron Rimar, M.D. ${ }^{1,3}$, Nina \\ Boulman, M.D. ${ }^{1,3}$, Lisa Kaly, M.D. ${ }^{1,3}$, Michael Rozenbaum, M.D. ${ }^{1,3}$, Itzhak Rosner, \\ M.D. ${ }^{1,3}$, and Gleb Slobodin, M.D. ${ }^{1,3 *}$ \\ ${ }^{\prime}$ Rheumatology Unit, Bnai Zion Medical Center, Haifa, Israel; ${ }^{2}$ Department of Nuclear Medicine, Bnai \\ Zion Medical Center, Haifa, Israel; and ${ }^{s}$ Ruth and Bruce Rappaport Faculty of Medicine, Technion, \\ Haifa, Israel
}

\begin{abstract}
ABST RACT
Sacroiliitis, inflammation of the sacroiliac joint (SIJ), is the hallmark of ankylosing spondylitis and spondy loarthritis (SpA) in general. The arsenal of recommended diagnostic modalities for imaging of the SIJ is scanty and, in practice, includes only conventional X-ray sand magnetic resonance imaging (MRI). This review suggests that bone scintigraphy, particularly single-photon emission computed tomography (SPECT) with calculation of indices, or SPECT in combination with low-dose computed to mography (CT) can be a sensitive and specific tool for the diagnosis of sacroiliitis and can be used as part of the individualized approach to the diagnosis of axial SpA. In addition, [18F]fluoride positron emission tomography (PET)/CT imaging and immunoscintigraphy, using labeled monoclonal anti-cy tokine antibodies, are promising methods of current scientific interest in this field.
\end{abstract}

KEY WORDS: Nuclear medicine, sacroiliitis, scintigraphy, spondyloarthritis, technetium, tomography

Abbreviations: AS, ankylosing spondylitis; CT, com puted tom ography; HIG, human immunoglobulin; MDP, m ethylene diph osphate; MRI, m agnetic resonance imaging; nrAxSpA, non-radiographic axial SpA; PET, positron em ission tom ography; SpA, spondyloarthritis; SIJ, sacroiliac joint; SPECT, single-photon em ission com puted tom ography.

Citation: Zilber K, Gorenberg M, Rimar D, Bou lman N, Kaly L, Rozenbaum M, Rosner I, Slobodin G . Ra dionuclide Meth ods in the Diagnosis of Sa croiliitis in Patients w ith Spondyloarthritis: An Update. Rambam Ma imonides Med J 2 016;7 (4):e0037. doi:10.5041/RMMJ.10264 Review

Copy right: (C) 2016 Zilber et al. This is an open-access article. All its content, except where otherwise noted, is distributed under the terms of the Creative Com mons Attribution License (http://creativecom mons.org/licenses/by/3.0), wh ich permits unrestricted u se, distribution, and reproduction in any m edium, prov ided the original work is properly cited.

Conflict of interest: No pot ential conflict of in terest relevant to this article was reported.

* Tow om correspondence sh ould be a ddressed. E-mail: g slobodin@yahoo.com 


\section{INT RODUCTION}

Sacroiliitis, inflammation of the sacroiliac joint (SIJ), the hallmark of ankylosing spondylitis (AS), may be present in the course of a variety of other rheumatic and non-rheumatic disorders as well. ${ }^{1}$ Clinical features of sacroiliitis includelow back and buttock pain, tenderness of the involved SIJ on palpation, and positive sacroiliac pain provocation tests, such as FABER (Flexion, ABduction, and External Rotation) or Gaenslen's maneuvers. Intense and disabling sacroiliac pain can be seen in patients with acute sacroiliitis, while insidious pain with night worsening, morning stiffness and improvement after exercise is more typical in patients with $\mathrm{AS}$ and other chronic rheumatic con ditions. ${ }^{2} \mathrm{How}-$ ever, these clinical features are not pathognomonic for sacroiliitis, and, in practice, only a minority of patients presenting with the above-mentioned complaints suffer from sacroiliitis. Hence, imaging has assumed a crucial role in the diagnosis of sacroiliac involvement in the disease process.

Presently, available methods for the imaging of sacroiliac joints are limited. Conventional radiography lacks sensitivity, particularly at the early stages of sacroiliitis; computed tomography (CT) scanning is not well validated for the diagnosis of sacroiliitis, demonstrates only structural changes, i.e. erosions and ankylosis, and is associated with relativ ely high radiation doses; and while magnetic resonance imaging (MRI) is able to show active inflammation before the consequent structural lesions dev elop, its sensitivity for detection of such changes is only moderate, at best only up to $70 \% .34$

Bone scintigraphy has been used to detect sacroiliitis for years. It has been appreciated for decades as a valuable method for the ascertainment of acute sacroiliitis, but its accuracy in the diagnosis of chronic inflammation in SIJ has always been questionable. A review on the performance of scintigraphy in assessing sacroiliitis in patients with AS, published in 2008, suggested that scintigraphy of the sacroiliacjoints is at most of limited diagnostic value for this diagnosis. 5 That review had a great impact and was the final step in establishing the singular dominance of MRI in the imaging of sacroiliitis. Only a few studies have aimed to investigate further the potential of radionuclide methods for the diagnosis of SIJ inv olvement since then. We believe, however, that at least some of these studies are importantfor the present and future practice of medicine. Accordingly, the aim of the present paper is to review and summarize the published medical literature since 2008 on the usage of radionuclide techniques for the diagnosis of sacroiliitis and spondyloarthritis (SpA) in general.

\section{MET HODS}

A systematic PubMed search using the keywords "sacroiliitis" or "spondyloarthritis" or "ankylosing spondylitis" in combination with "bone scintigraphy" or "bone scan" was performed and relevant articles extracted and critically assessed. The data were further summarized and presented.

\section{RESULTS}

\section{Bone Scintigraphy with Technetium-99m-} labeled Methylene Diphosphate

This method can demonstrate increased radionuclide uptake in the areas of accelerated bone turnover due to any cause, including inflammation. During the examination of the SIJ, the intensity of radionuclide uptake in the area of interest is compared to an adjacent background structure, usually sacrum, allowing quantitative interpretation of the result. Due to the low sensitivity of about $50 \%$ and calculated positivelikelihood ratio of about 3 for the diagnosis of sacroiliitis, this method of SIJ imaging was suggested to be oflimited, if any, value by Song et al., in 2008.5 Of interest, however, even then, in patients with earlier stages of radiographic sacroiliitis, those where the realneed in the confirmatory imaging exists, the sensitivity of bone scan was calculated as closer to $60 \%$. In addition, as a possible limitation of the analysis, MRI was chosen as the gold standard for the assessmentof bone scan performance for SIJ imaging in some of the reviewed studies, while it is well accepted today that MRI itself has sensitivity of only about $70 \%$ for the diagnosis of sacroiliitis. ${ }^{3-5}$ Subsequently, Song et al. reported in 2010 their own retrospective study on the performance of radionuclide scan in 207 patients with chronic low back pain for the diagnosis of SpA. ${ }^{6}$ In this study, where the rheumatologist's diagnosis was chosen as the gold standard, sensitivities of scintigraphy for any (unilateral or bilateral), bilateral, and isolated unilateral sacro iliitis were $64.9 \%, 40.2 \%$, and $24.7 \%$, respectively. Respective specificities were 50.5\%, 57.7\%, and $92.8 \%$, resulting in likelihood ratios of $1.3,1.0$, and 3.4 .6 In another study, specificity of quantitative scintigraphy in 30 patients with MRI-positive nonradiographic SpA was calculated as $100 \%$, while 
sensitivity of the method was only $32 \% .7$ Finally, the diagnostic potential of bone scintigraphy to elucidate unappreciated articular and entheseal involvement in addition to the imaging of the SIJ in SpA was examined and found useful in the study of Gheita et al., 8 thus offering an additional benefit of this modality.

\section{Single-Photon Emission Computed Tomography}

It has been known for years that single-photon emission computed tomography (SPECT) imaging increases sensitivity of bone scintigraphy, allowing slice-by-slice three-dimensional radionuclide uptake analy sis. This possibility can be particularly useful in the study of the SIJ, where complex anatomy is probably the main cause of low accuracy of both plain radiography and bone scintigraphy (Figure 1). In the only recent report, SPECT of SIJ with calculated indices of uptake had sensitivity of $80 \%$ and specificity of $97 \%$ for sacroiliitis in 46 patients with chronic low back pain. 9

\section{Com bined SPECT/CT Imaging}

A combination of SPECT and CT has been used in various fields in medicine for functional and anatomical imaging; SPECT/CT has further increased specificity compared with SPECT in clinical practice by conjoining the anatomicalinformation provided by CT and permitting better characterization of equivocal lesions. The SPECT/CT combination has been suggested previously as a useful diagnostic modality for the evaluation of sacroiliac dysfunction. ${ }^{10}$ In a study involving 20 patients with early SpA, diagnosed by Amor criteria, SPECT/CT of SIJ demonstrated reliable reproducibility, sensitivity of $80 \%$, and specificity of $84 \%$ for SIJ involvement. ${ }^{11}$ Of importance, low-dose CT, minimizing the radiation exposure, was used in this study.

\section{Positron Em ission Tomography}

The [ $\left.{ }^{18} \mathrm{~F}\right] \mathrm{FDG}$ positron emission to mography (PET)/ CT technique has been examined previously as an additional toolfor the diagnosis of enthesitis in SpA patients. ${ }^{12}$ As a modality for the diagnosis of sacroiliitis, [18F]FDG PET/CT has been shown to be of little value, with negative results in all 10 patients with ankylosing spondylitis (AS) in one study, ${ }^{13}$ showing inconsistent results in another, ${ }^{14}$ and assessed as not useful for predicting response to TNF-alpha antagonist therapy in a third study. ${ }^{15}$ However, $\left[{ }^{18} \mathrm{~F}\right]$ fluoride, which is a bone tracer of osteoblastic activity, was found useful for demonstrating bone activity in AS patients. ${ }^{13}$ Of importance, the lesions detected by $\left[{ }^{18} 8\right]$ fluoride PET/CT did not always correlate with bone marrow edema as seen on MRI, suggesting that this modality may reflect bone formation rather than inflammatory processes in AS patients. ${ }^{13,16}$ An additional study ex amined performance of $[18 \mathrm{~F}]$ fluoride PET/CT in 10 patients with non-radiographic axial SpA (nrAxSpA) and 5 patients with AS: PET/CT was reported as positive in all AS patients and negative in all nrAxSpA patients, further suggesting specificity of this imaging for bone formation, rather than for inflammation. ${ }^{17}$ The sensitivity, specificity, and accuracy of [18F]fluoride PET/CT for detection of sacroiliitis was calculated as $80 \%, 77 \%$, and $79 \%$, respectively, in another study, involving $15 \mathrm{AS}$ patients. ${ }^{18}$

\section{Bone Scintigraphy with Technetium-99m- labeled Anti-TNF-alpha}

The first report on the use of monoclonal human anti-TNF-alpha antibody labeled with Tc-99m for the diagnosis of nrAxSpA was published in 2014.19 In a study involving 15 patients with axial and peripheral SpA examined with a similar immunoscintigraphic method, radionuclide uptake of anti-
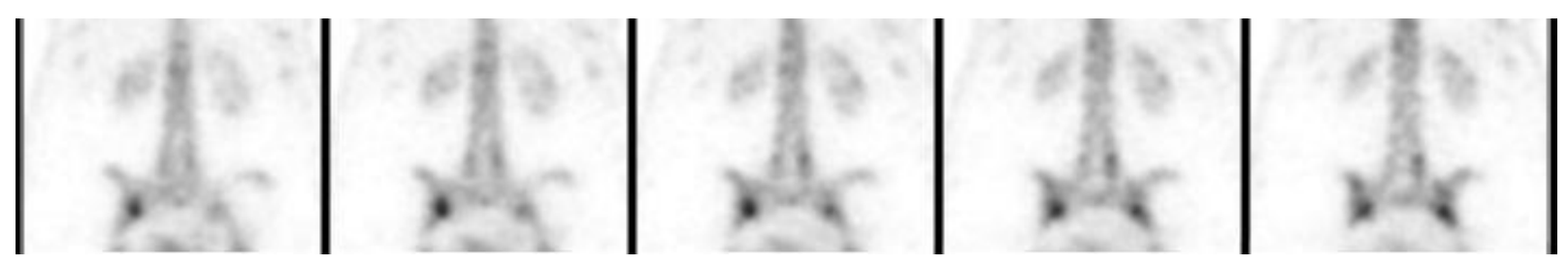

Figure 1. Technetium-99m-MDP SPECT in Ankylosing Spondylitis.

Technetium-99m-MDP SPECT shows increased uptake in both sacroiliac regions in a patient with ankylosing spondylitis. 
TNF-alpha correlated well with clinical, sonographic, and MRI findings. ${ }^{20}$

\section{Bone Scintigraphy with Technetium-99m- labeled Hum an Immunoglobulin}

Analogous to monoclonal human anti-TNF-alpha antibodies, human immunoglobulin (HIG) is expected to accumulate in the areas of active inflammation and, when labeled with Tc-99m, can be detectedby a scanner. The only pilot study using this modality in five AS patients suggested that the method can have value in the diagnosis of acute inflammation of SIJ.21

\section{DISCUSSION}

The diagnosis of SpA can be challenging. The combination of a characteristic clinical presentation, elevated C-reactive protein/erythrocyte sedimentation rate, and positive imaging may enable first-visit diagnosis by rheumatologists in many patients. But in others, particularly at the early stage of the disease, the path to the diagnosis is much more complicated. A rheumatologist, in the absence of widely accepted diagnostic criteria for axial SpA, may have to decide whether to adhere strictly to the restrictive 2009 classification criteria 3 and use them for the diagnosis, or, at least in some patients, to look for additional evidence for disease presence, utilizing tools that are less validated. The latter approach may benefit the patient with an early diagnosis, unachievable by resorting to the too specific and less sensitive classification criteria.
The presence of sacroiliac involvement is a cornerstone in the diagnosis of axial SpA. The positive imaging of sacroiliitis, as a confirmation of suspected SpA, is always looked for by a rheumatologist. As was noted above, at present the spectrum of recommended SIJ imaging modalities to this end is scanty and, in practice, includes only conventional X-rays and MRI. From this viewpoint, the addition of another validated tool for assessing the SIJ would be of primary importance. The present review suggests that bone scintigraphy, particularly SPECT with calculation of indices, or SPECT in combination with low-dose CT can be a sensitive and specific tool for the diagnosis of sacroiliitis, particularly in patients with equivocalor negative MRI examination of SIJ (Table 1). Of course, controlled studies examining the positive and negative predictive values of the suggested algorithm in different subsets of patients with suspected SpA should be performed. However, in our opinion, these radionuclide methods can have a place in the individualized approach to SpA diagnosis and should not be neglected.

The contribution of radionuclide methods to future scientific research in this field seems promising as well. Studies using $\left[{ }^{18} \mathrm{~F}\right]$ fluoride PET/CT imaging in SpA will, hopefully, help to clarify details of new bone formation in SpA. In addition, immunoscintigraphy, using labeled monoclonal anticy tokine antibodies, may contribute to the understanding of SpA pathophysiologic processes at different disease stages and in patient subsets, as

Table 1. Reported Performance of Radionuclide Methods for the Diagnosis of Sacroiliitis.

\begin{tabular}{|c|c|c|c|c|}
\hline Ref. & Method & Patients & Sensitivity (\%) & Specificity (\%) \\
\hline 6 & $\begin{array}{l}\text { Quantitative bone } \\
\text { scintigraphy with } \\
\text { technetium-99m-MDP }\end{array}$ & 207 & $\begin{array}{l}\text { Any sacroiliitis, } 64.9 \\
\text { Bilateral sacroiliitis, } 40.2 \\
\text { Unilateral sacroiliitis, } 24.7\end{array}$ & $\begin{array}{l}\text { Any sacroiliitis, } 50.5 \\
\text { Bilateral sacroiliitis, } 57.7 \\
\text { Unilateral sacroiliitis, } 92.8\end{array}$ \\
\hline 7 & $\begin{array}{l}\text { Quantitative bone } \\
\text { scintigraphy with } \\
\text { technetium-99m-MDP }\end{array}$ & 30 & 32 & 100 \\
\hline 9 & $\begin{array}{l}\text { Single-photon emission } \\
\text { computed tomography } \\
\text { (SPECT) }\end{array}$ & 91 & 80 & 95 \\
\hline 11 & $\begin{array}{l}\text { Combined SPECT /CT } \\
\text { imaging }\end{array}$ & 20 & 80 & 84.6 \\
\hline 18 & $\begin{array}{l}\text { Positron emission } \\
\text { tomography (PET)/CT }\end{array}$ & 15 & 80 & 77 \\
\hline
\end{tabular}

$\mathrm{CT}$, computed tomography; MDP, methylene diphosphate; SPECT, single-photon emission computed tomography 
well as aid individualization of the choice of biological treatment in the near future.

In summary, the spectrum of existing radionuclide tools for the evaluation of patients with SpA - both highly sensitive and specific methods for its diagnosis in the clinical setting and new promising techniques for scientific research-is expanding and promises further progress in the study of axial SpA.

\section{REFERENCES}

1. Tuite MJ. Sacroiliac joint imaging. Semin Musculoskelet Radiol 2008;12:72-82. Full Text

2. Slobodin G, Rim ar D, Boulman N, et al. Acutesacroiliitis. Clin Rheumatol 2016;35:851-6. Full Text

3. Rudwaleit M, van der Heijde D, Landew R, et al. The dev elopment of Assessment of Spondy loArthritis International Society classification criteria for axial spondy loarthritis (part II): validation and final selection. Ann Rheum Dis 2009;68:777-83. Full Text

4. Jans L, Coem an L, Van Praet L, et al. How sensitive and specific are MRI featu res of sacroiliitis for diagnosis of spondy loarthritis in patients with inflam matory back pain? JBR-BTR 2 014;97:2 02-5.

5. Song IH, Carrasco-FernándezJ, Rudwaleit M, Sieper $\mathrm{J}$. The diagnostic value of scintigraphy in assessing sacroiliitis in ankylosing spondylitis: a sy stem atic literature research. Ann Rheum Dis 2008 ;67:153540. Full Text

6. Song IH, Brandt H, Rudwaleit M, Sieper J. Limited diagn ostic value of unilateral sacroiliitis in scintigraphy in assessing axial spondyloarthritis.J Rheumatol 2010;37:1200-2. Full Text

7. Akdeniz O, Alayli G, Tosun FC, et al. Early spondyloarthropathy: scintigraphic, biological, and clinicalfindings in MRI-positive patients. Clin Rheumatol 2008;27:469-74. Full Text

8. Gheita TA, Azkalany GS, Kenawy SA, Kandeel AA. Bone scintigraphy in axial seronegative spon dy loarthritis patients: role in detection of subclinical periph eral arthritis and disease activity. Int $J$ Rheum Dis 2015;1 8:553-9. Full Text

9. Koç ZP, Kin Cengiz A, Aydın F, et al. Sacroiliac indicis increase the specificity of bone scintigraphy in the diagnosis of sa croiliitis. Mol Im aging Radionucl Ther 2015;24:8-14. Full Text

10. Tofuku K, Koga H, Komiy a S. The diagnosticvalue of single-photon emission computed tomography / computed tomography for severe sacroiliac joint dy sfunction. Eur Spine J 2015;24:859-63.
11. Kim YI, Suh M, Kim YK, Lee HY, Shin K. The usefulness of bone SPECT/CT imaging with volu me of interest analysis in early axial spondy loarthritis. BMC Musculoskelet Disord 2015;16:9. Full Text

12. TaniguchiY, Arii K, Kum on Y, et al. Positron emission tom ography/computed tomography: a clinical tool for evaluation of enthesitis in patients with spondy loarthritides. Rh eumatology (Oxford) 2010; 49:348-54. Full Text

13. Bruijnen ST, van der Weijden MA, Klein JP, et al. Bone form ation rather than inflamm ation reflects ankylosing spondylitis activity on PET-CT: a pilot study. Arthritis Res Ther $2012 ; 14:$ R71 . Full Text

14. Vijayant V, Sarma M, Aurangabadkar H, Bichile L, Basu S. Potential of (18)F-FDG-PET as a valuable adjunct to clinical and response assessment in rheumatoid arthritis and seron egative spondy loarthropathies. World J Radiol 2012;4:462-8. Full Text

15. Darrieutort-Laffite C, Ansquer C, Maugars Y, Le Goff B, Bodere F, Berthelot JM. Sodium (18)F-sodium fluoride PET failed to predict responses to TNFa antagonist therapy in 31 patien ts with possible spondy loarthritis not meeting ASAS criteria. Joint Bone Spine 2015;82:411-16. Full Text

16. Fischer DR, Pfirrmann CW, Zubler V, et al. High bone turnover assessed by $18 \mathrm{~F}$-fluoride PET/CT in the spine and sacroiliac joints of patients with ankylosing spondy litis: com parison with inflam matory lesions detected by whole body MRI. EJNMMI Res 2012;2:38. Full Text

17. Toussirot E, Caoduro C, Ungureanu C, Michel F, Runge M, Boulahdour H. 18F-fluoride PET/CT assessment in patients fulfilling the clinical arm of the ASAS criteria for axial spondy loarthritis. A com parative study with ankylosing spondy litis. Clin Exp Rheumatol 2015;33:588.

18. Strobel K, Fischer DR, Tamborrini G, et al. 18Ffluoride PET/CT for detection of sacroiliitis in ankylosing spondylitis. Eur J Nucl Med Mol Imaging 2010;37:1760-5. Full Text

19. de Andrade AlexandreDJ, de Souza SA, Moraes do Carmo CC, et al. Use of (99m)Tc-anti-TNF- $\alpha$ scintigraphy in a patient with non-radiographic axial spondy loarthritis. Ann Nucl Med 2014;28:936 -9. Full $\underline{\text { Text }}$

20. Carron P, Lambert B, Van Praet L, et al. Scintigraphic detection of TNF-driv en inflam mation by radiolabelled certolizumab pegol in patients with rheumatoid arthritis and spondy loarthritis. RMD Open 2016;2:e000265. Full Text

21. Ozdoğan O, Değirmenci B, Senocak O, et al. Tc-99m HIG scintigraphy in detection of active inflammation in ankylosing spondylitis. Mol Imaging Radionucl Ther 2011;20:52-8. Full Text 